\title{
The Synthesis of 3,3'-Dimethyl (p-guanidino) Dicyclohexylmethane
}

\author{
Yongli PENG, \\ School of Materials Science and Engineering \\ Wuhan Institute of Technology \\ Wuhan, China \\ e-mail: PYL68@163.com
}

\author{
Yajiao ZHANG \\ School of Materials Science and Engineering \\ Wuhan Institute of Technology \\ Wuhan, China \\ e-mail: zayajaqa@163.com
}

\begin{abstract}
The addition reaction was carried out under the acidic conditions using dicyandiamide and 3,3'-dimethyl-4,4'diaminodicyclohexylmethane (DMDC) as raw materials to prepare 3,3'-dimethyl P-guanidino) dicyclohexylmethane. The effects of reaction temperature, reaction time and molar ratio of materials on the yield of the product were discussed. The products were characterized by IR spectra and NMR spectra. The results showed that the optimum reaction conditions were as follows: reaction temperature $130{ }^{\circ} \mathrm{C}$, reaction time $9 \mathrm{~h}$, the optimum acidity is concentrated hydrochloric acid in an amount of 1:1.1, $n$ (DMDC): $n$ (Dicyandiamide) $=1: 2$. Under these conditions, the yield of crude product was $81.3 \%$.
\end{abstract}

Keywords-dicyandiamide; 3,3'-dimethyl-4, diaminodicyclohexylmethane; latent curing agent

\section{INTRODUCTION}

Big guanidine substances have been recognized and applied has a long history[1-3], the synthesis method has multiple[4]. Big guanidine and its derivatives are mainly through the amine and dicyandiamide in the acidic conditions of the addition reaction[1,5]. Canada Olivier LeBel and so on with aniline and dicyandiamide in acidic conditions, heating reaction, after cooling to obtain 1-phenyl guanidine hydrochloride, the product with tetrahydrofuran, n-hexane and acetone after the addition of methanol solution of sodium methoxide to obtain the purity of $95 \%$ of the phenyl biguanide[6]. DMDC is an alicyclic amine type curing agent, with a saturated six-membered ring structure, at the same time with a space conformation, good flexibility and so on, but also has a similar structure with the aromatic amine-ring structure of the rigidity and strength. At present, there are few reports on the basic structure and properties of alicyclic amine curing agent[7]. In this paper, dicyandiamide and DMDC were used as raw materials to prepare directly through dicyandiamide and amide in acidic environment, the synthesis of a new type of biguanide epoxy resin curing agent[8]. The method of raw materials cheap, easy to prepare, with a wide range of applications.

\section{EXPERIMENTAL SECTION}

\section{A. Materials}

$\begin{array}{lcc}\text { Dicyandiamide(Pure chemical) } & \text { were provided by } \\ \text { industrial } & \text { corporation; } & 3,3 \text { '-dimethyl-4,4'- }\end{array}$

Aladdin industrial corporation; 3,3'-dimethyl-4,4'-

diaminodicyclohexylmethane (DMDC) was purchased from Shenzhen City Industry Asahi Industrial Co., Ltd. Hydrochloric acid; Deionized water(RO, Youpu ultra pure water manufacturing system).

\section{B. Synthetic principle}

Dicyandiamide contains cyano and DMDC molecules contain amino groups. The lone pair electrons of the nitrogen atoms in the amino group tend to attack the carbon positive ions. Both under certain conditions can occur nucleophilic addition reaction, resulting in biguanide curing agent.

First, the use of concentrated hydrochloric acid and dicyandiamide salt, dicyandiamide carbon nitrogen three bonds on the nitrogen atoms of the lone pair of electrons to attack hydrogen ions, so that dicyandiamide salt. After the salt is added to the DMDC, the amino group in the DMDC has a nucleophilicity. Since the electron cloud of the carbonyl bond in the dicyandiamide is more polarized to the nitrogen atom, the carbon atom is positively charged and is favorable to the nucleophile attack. The amino group in the DMDC attacks the carbon-nitrogen triple bond of dicyandiamide and undergoes an addition reaction to produce a biguanide derivative.

\section{Synthesis of 3,3'-dimethyl P-guanidino) dicyclohexylmethane}

The synthesis route of 3,3'-dimethyl-4,4'ditoguanidobicyclohexylmethane is shown in Figure 1. First, $20 \mathrm{~mL}$ of distilled water is taken with a graduated cylinder and poured into a three-necked flask. Rose to 60 degrees. Start adding $1.85 \mathrm{~g}$ of dicyandiamide to the flask, stirring it to dissolve quickly, and adding a condensing reflux device. $1.85 \mathrm{~mL}$ of concentrated hydrochloric acid $[\omega(\mathrm{HCl})=36.5 \%]$ was taken as a pipette and added to a three-necked flask and allowed to react for $1 \mathrm{~h}$ to make dicyandiamide salt. After that, $2.43 \mathrm{~g}$ of DMDC was weighed and dissolved in $30 \mathrm{~mL}$ of distilled water and added dropwise to a three-necked flask for 8 hours. After the completion of the reaction, a rotary evaporation experiment was carried out to remove the distilled water and the unreacted completely DMDC to obtain a pale yellow viscous liquid. Finally, recrystallization was carried out by suction filtration, washing and drying at $70^{\circ} \mathrm{C}$ to obtain a white granular solid, and the yield was calculated. 


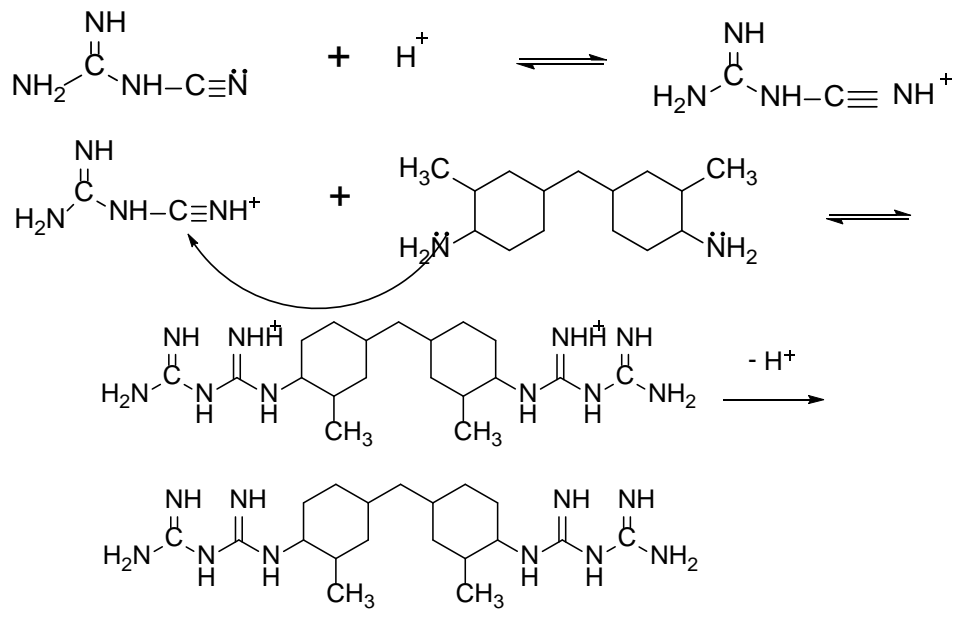

Figure 1. DMDC reaction with dicyandiamide.

\section{CHARACTERIZATION}

Through the infrared spectrum of Figure 2 and Table 1, it can be seen that the cured product has strong absorption peak at $3000 \sim 3500 \mathrm{~cm}-1$, which is basically the same as dicyandiamide, which indicates that when DMDC reacts with dicyandiamide, The primary amine in the cyanamide did not react with the imine. At the same time, there was no characteristic absorption peak near the $2200 \mathrm{~cm}-1$ in the infrared spectrum of the modified product, where the dicyandiamide had a strong absorption peak and a stretching vibration of carbon-nitrogen triple bond. In addition, the absorption peak of the carbon-nitrogen double bond near $1500 \sim 1675 \mathrm{~cm}-1$ is enhanced, indicating that the cyano group in the dicyandiamide undergoes the addition reaction, and the carbon-nitrogen triple bond reaction is a double bond. The above analysis shows that DMDC and dicyandiamide occurred nucleophilic addition reaction, carbon and nitrogen triple bond is opened to generate a carbon-nitrogen double bond, obtained 3,3'-dimethyl (p-guanidino) dicyclohexylmethane, a new latent curing agent.

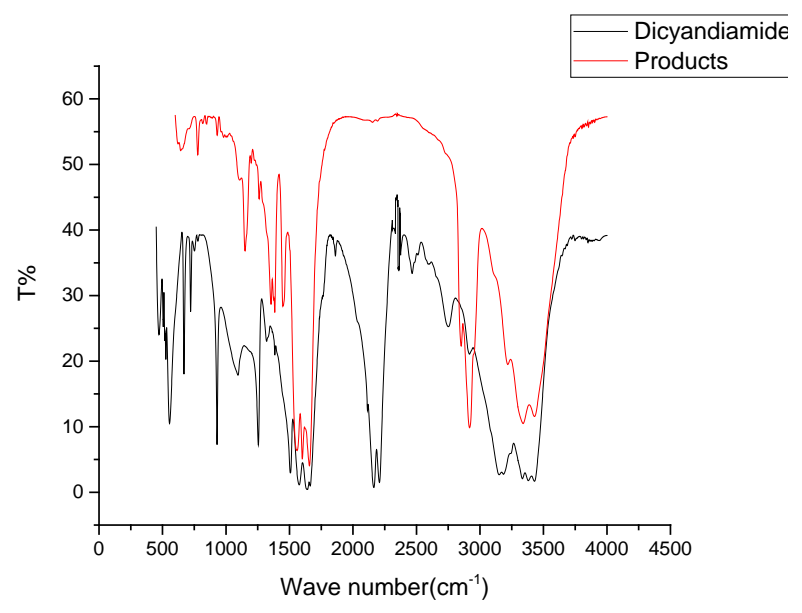

Figure 2. FTIR spectra of dicyandiamide and products.
Figure 3 shows the NMR spectrum of the 3,3'-dimethyl (p-guanidino) dicyclohexylmethane molecule. The solvent was analyzed by deuterated dimethylsulfoxide (DMSO) as shown in Table 2. The integral of the absorption peak The ratio of the area is consistent with the number of $\mathrm{H}$ in the corresponding position of 3,3'-dimethyl (p-guanidino) dicyclohexylmethane to prove that the obtained material is 3,3'-dimethyl (p-guanidino) dicyclohexylmethane.

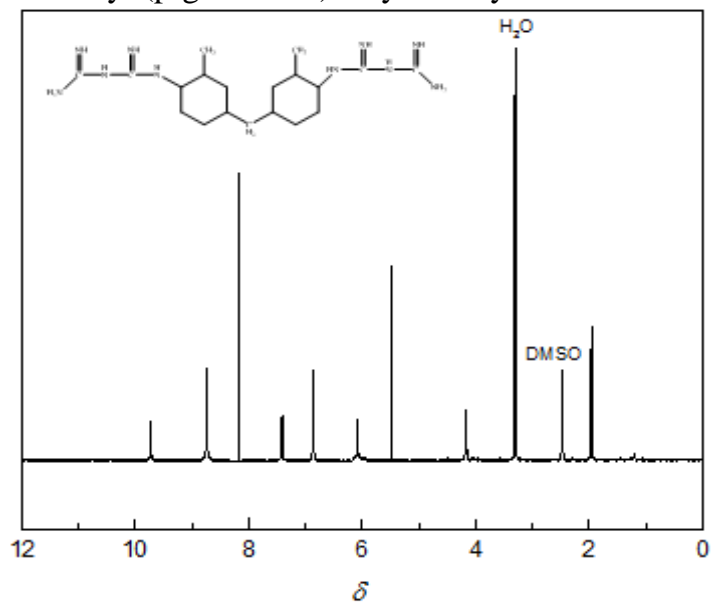

Figure 3. 1H-NMR spectrum of 3,3'-dimethyl (p-guanidino) dicyclohexylmethane.

\section{RESULTS AND DISCUSSION}

\section{A. Reaction Influencing Factors}

In this experiment, the orthogonal experiment was used to study the effect of reaction time, reaction temperature and feed ratio on the yield of the reactants. The optimal combination scheme was found by the results analysis. Table 3 shows the yield of 3,3'-dimethyl(p-guanidino) dicyclohexylmethane as an index, At the average room temperature of 20 to $25^{\circ} \mathrm{C}$, the reaction time (A), reaction temperature (B), feed ratio (C) as the three factors, the selection of three levels of three experimental tables. 
TABLE I. INFRARED CHARACTERISTICS OF THE PRODUCT AFTER MODIFICATION

\begin{tabular}{cc}
\hline Absorb Position $\left(\mathrm{cm}^{-1}\right)$ & Attribution Statement \\
\hline $3300 \sim 3500$ & N-H Stretching Vibration \\
$2700 \sim 3000$ & C-H Stretching Vibration \\
$1500 \sim 1700$ & C=N Stretching Vibration \\
$1300 \sim 1500$ & C-N Bending Vibration \\
1100 & C-C Skeleton Vibration \\
\hline
\end{tabular}

TABLE II. CHEMICAL SHIFTS OF H ATOMS OF 3,3'-DIMETHYL (P-GUANIDINO) DICYCLOHEXYLMETHANE IN 1H-NMR

\begin{tabular}{ccc}
\hline serial number & $\delta$ & number of $\mathrm{H}$ \\
\hline 1 & 9.73 & 2 \\
2 & 8.81 & 4 \\
3 & 8.22 & 12 \\
4 & 7.46 & 2 \\
5 & 6.88 & 2 \\
6 & 6.16 & 6 \\
7 & 5.62 & 2 \\
\hline
\end{tabular}

TABLE III. FACTORS AND LEVELS

\begin{tabular}{cccc}
\hline Level & Reaction Time $/ \mathrm{h}$ & Temperature Reflex $/{ }^{\circ} \mathrm{C}$ & Feeding Ratio \\
\hline 1 & 8 & 120 & $1: 1.8$ \\
2 & 9 & 130 & $1: 2$ \\
3 & 10 & 140 & $1: 2.2$ \\
\hline
\end{tabular}

TABLE IV. EFFECTS OF ACIDITY ON THE PRODUCT

\begin{tabular}{ccccc}
\hline Molar Ratio & $1: 0.8$ & $1: 1$ & $1: 1.1$ & $1: 1.2$ \\
\hline Yield/\% & 76.5 & 80.2 & 81.3 & 74.6 \\
\hline
\end{tabular}

Therefore, the optimum reaction conditions were as follows: synthesis reaction time was 9h, reaction temperature was $130^{\circ} \mathrm{C}$, raw material feeding ratio was $1: 2$.

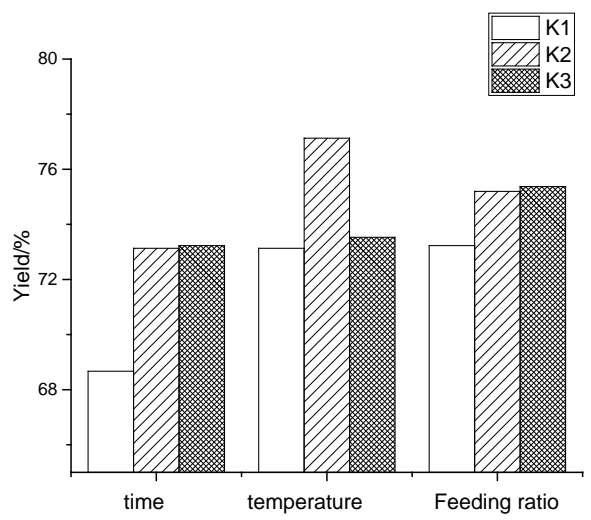

Figure 4. Comparison of yield trends under different experimental factors.

\section{B. Effect of Acidity on the Yield of Reactants}

In the orthogonal optimization experiment, the molar ratio of dicyandiamide to concentrated hydrochloric acid was $1: 1$, and the molar ratio of dicyandiamide to concentrated hydrochloric acid was 1:0.8, 1:1.1, 1:1.2, The process conditions are unchanged and the results are shown in Table 4.

On the basis of the above table, the production line with the acidity of the change in the line graph, can better see the acidity changes, the cured product yield trends, the results show from Table 3 and the line chart can be seen in the acidity is not large, with the increase in acidity, yield gradually increased, but to a certain extent, the yield has dropped down. Because the acidity is small, dicyandiamide salt, cyanide protonation of the high degree of dominance, is conducive to the occurrence of nucleophilic addition reaction. In addition, the acid also plays a catalytic role in the reaction to accelerate the reaction. However, when the acidity of the system is too large, the amino groups in the DMDC combine 
with the proton as the amino ion, reduce the nucleophile concentration, and hydrolyze at the same time to form the byproduct imidazuronyl. The optimum acidity condition is when the molar ratio of dicyandiamide to concentrated hydrochloric acid is 1: 1.1, and the yield is $81.3 \%$ in Figure 5.

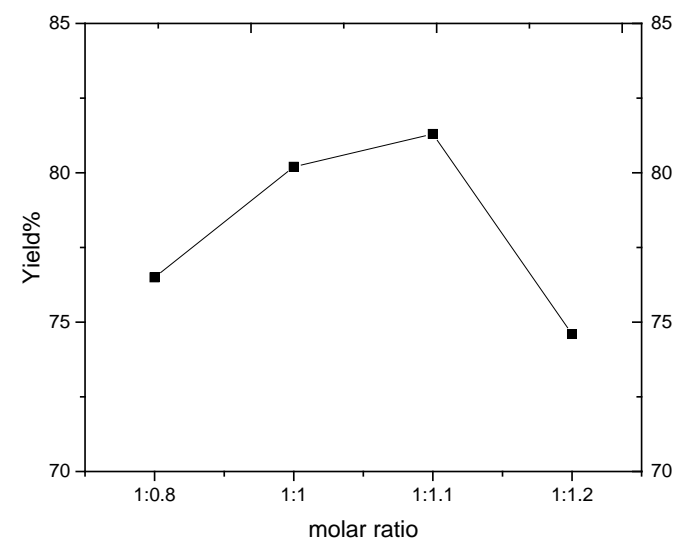

Figure 5. Effect of acidity on yield.

\section{CONCLUSION}

Based on the principle of nucleophilic addition reaction, the big guanidine curing agent 3,3'-dimethyl (p-guanidino) dicyclohexylmethane was designed and synthesized. The carbonitride of dicyandiamide was analyzed by infrared spectroscopy The reaction of the three bonds, while carbon and nitrogen double bond peaks strengthened, proved that the synthesis of the target product. In addition, the optimum technological conditions were obtained: the reaction time was $9 \mathrm{~h}$, the reaction temperature was $130^{\circ} \mathrm{C}$, the feed ratio was $n$ (DMDC): $n$ (Dicyandiamide) $=1: 2$, and the effect of acidity on the yield of the composites was also studied, the optimum acidity is concentrated hydrochloric acid in an amount of $1: 1.1$, at which time the product yield is $81.3 \%$.

\section{ACKNOWLEDGMENT}

We thank financial support from National Natural Science Foundation of China (21302150), Hubei Provincial Department of Education (D20131501), Scientific Research Foundation for Returned Overseas Chinese Scholars, State Education Ministry [2012]1707, President Foundation of Wuhan Institute of Technology (2014038), Foundation of ChutianDdistinguished Fellow from Hubei Provincial Department of Education, Foundation of High-end Talent Cultivation Program from Wuhan Institute of Technology.

\section{REFERENCES}

[1] F.H.S. Curd and F.L.Rose.UK Patent 581346, 1946.

[2] C.G.Overberger, F.W.Michelotti, and P.M. Carabateas. J.Am.Chen.Soc.79, 941-941.

[3] P.Hubberstey and U.Sukangpanya. Struct. Bond. 111, 33(2004).

[4] Olivier LeBel, Thierry Maris, Hugues Duval. A practical guide to arlbiguanides-Synthesis and structural characterization. Can.J.Chen. : 83(2005)615-625.

[5] Stanislas Mayer, Denis M. Daigle, Eric D. An Expedient and Facile One-Step Synthesis of a Biguanide Library by Microwave Irradiation Coupled with Simple Product Filtration. Inhibitors of Dihydrofolate Reductase.J.Comb.Chem.:6(2004), 776-782.

[6] OLIVIER LEBEL, THIERRY MARIS, HUGUES DUVAL. A practical guide to arylbiguanides- synthesis and structural characterization [J]. Canadian Journal Chemistry, 2005, (83): 615-625.

[7] Glibert M D, Schneider N S. Macromolecules, 1996, 24: 360-369.

[8] Shi Xuetang, Wu Xuemei, He Gaohong,. Study on the properties of mannich modified IPDA epoxy curing agent [J]. Chemistry and Adhesion, 2008, 30(5): 8-11. 